\title{
Sustainable systems - game theory as a tool for preserving energy resources
}

Martin Dolinsky

\begin{abstract}
Background: Mankind is highly dependent upon fossil fuels for its ever-increasing energy demands. The future supply is unreliable mainly due to the fact that it is a finite resource which is becoming more and more expensive to produce. As a reaction to this current threat and uncertainty, a mathematical model is developed in this study in order to identify more sustainable quantities. The main objective of this study was to provide companies with a tool to assist in the prevention of overproduction, in other words, to minimize unsalable production quantities and to preserve natural resources.
\end{abstract}

Method: Regression analysis, game theory - Cournot game.

Results: The study was carried out in cooperation with the Italian company PintInox, S. p. A., located in the Italian region of Lombardia. After the implementation of sustainability measurement metrics into the company's processes and the discovery of a profitable market niche (market principles applying value to sustainable development) for PintInox, S. p. A., a natural grouping (oligopoly) of Italian cutlery producers was identified. Entrance barriers posed by this group (oligopoly) are all kinds of inabilities to prove a verifiable concept of their Corporate Social Responsibility practices. Companies that failed to communicate their commitment regarding sustainable development to their business-to-business (B2B) partners cannot enter this oligopoly and are, consequently, excluded from markets placing value on sustainability principles. Based on economic effectiveness, the marketable output of every oligopoly member was calculated.

Conclusions: The desire to preserve natural resources is driven by incentives within the marketplace. These incentives were identified through the game theory. The companies firstly concentrate themselves on social responsibility and environmental safety and then, as oligopoly members, on economic effectiveness. The study reconfirms that also the economic dimension plays an important role in a 'triple bottom line' philosophy.

Keywords: Oligopoly; Cournot game; Game theory; Corporate Social Responsibility

\section{Background Introduction}

This paper has an ambition to fill the gap in research activities in regard to sustainable development. Many studies in this field contain an economic dimension. Just to mention some of the institutions and their contributions: the Institute for Environmental Decisions from Zurich dealt with the topic 'Economic and environmental benefits of dry discharge of bottom ash and acid washing of fly ash from municipal solid waste incineration in Switzerland, the Department of Energy Engineering from The University

Correspondence: martin.dolinsky@sustainability.sk

Department of Management and Marketing, Faculty of Economics and

Business, Pan-European University, Tematinska 10, 85105 Bratislava, Slovakia of Florence worked on the 'Economic Assessment of Innovative Processes for Biomethane Production', the Faculty of Civil Engineering and Geosciences from The Delft University of Technology on the 'Economic and Carbon Footprint Evaluation of Thin Stillage Treatment', CIRSEE Suez Environnement on the 'Technical and Economic Assessment of Micro-cogeneration Technologies for Sewage Biogas', and the Deutsches Biomasseforschungszentrum (gemeinnützige $\mathrm{GmbH}$ ) from Leipzig on the 'Environmental Impacts and Economic Feasibility of Producing Bioenergy under Various Frame Conditions' [1]. All the mentioned studies contained 
integrative assessments. The aim of the economic parts of the integrative assessments was the selection of the most feasible investment strategy, whilst classical financial indicators were used to determine the economic feasibility (e.g., simple cost analyses, net present value analyses, payback period anticipation, capital expenditure analyses). However, none of them paid scientific attention to a rigorous analysis of the real market situation. Economic issues were considered only from the company's perspective, and the market perspective was neglected. In spite of this, we can find only a few contributions studying the market situation and solving different problems in a manner which is attempted in this paper. The paper 'Environmental innovation under Cournot competition' from June 2007 contains a unique market approach. According to the comments of the authors who presented this paper, contrary to the existing literature, a market approach was used in modeling the interaction between the output market, where companies play á la Cournot, and the emission permit market [2]. The authors make mention that besides their contribution, only Montero's article takes into account a strategic interaction in the output market [3]. Sanin and Zanaj correlate output market revenues and revenues or costs from trading in the permit market. This paper, in contrary, examines the total costs of the production and revenues from selling in a market evaluating the triple bottom line of sustainability. In this paper, a concrete case of the potential success/failure of a business strategy oriented on sustainable development is investigated under market conditions.

\section{The role of a game theory in sustainability}

Mathematical models can help preserve the Earth's resources. A game theory (i.e., an interactive decision theory) can play an important role in the preservation of energy resources - through its ability to identify the salable quantities and consequently minimize energy consumption. Today, fossil resources are not considered to be a perspective natural resource for a sustainable future. On the one hand, there are countries that are prominent users of oil, such as the USA, becoming almost net exporters of oil; but what is the price paid for the self-sufficiency in strategic commodities? Energy Return on Investment (EROI) would be a partial answer to this question. During the 1950s in the USA, every barrel of oil invested in exploration had led to the discovery of about 50 or more, and in 1990, a ratio of one to five [4]. In other words, different deposits are characterized by different cost levels of production. We are depleting the most accessible supplies first and then investing more and more energy into the extraction of less accessible resources. This paper offers a solution of how to circumvent the problem of the scarcity of resources by providing companies with guidance on how to better match the production setup to the customer's needs - this is precisely the role that the game theory can play in sustainable development. An application of the game theory (Cournot game) would lead to less energy resources being consumed since it would help a company to better prevent excessive (not needed) production. Our solution is economically driven based on the presumption that companies will always want to lower production costs by consuming less raw material. 'One (opinion) group argues from an economic point of view with the goal of breaking the dependency on a feedstock that is becoming scarcer and more contentious'. This economic view is presented by Sandholzer and Narodoslawsky in the literature [5]. In general, it is also cost-effectiveness (not solely altruism) which drives companies to optimize their setup of production under the requirements of sustainable development. Environmental economists are now solving the question - how large, in its physical dimensions, should the economic system be in relation to the ecosystem that sustains it [4]? To answer this question, one has to link together economic and ecological indicators, and that is also the focus of this paper.

\section{The role of an ecological footprint in the relationship between economics and ecology}

In order to be able to create a link between economic activities and their environmental impact, we need an appropriate indicator. Our research outcomes were tested along with the management of an Italian small- and medium-sized enterprise (SME) PintInox, S. p. A. For assessment purposes, we were searching for an indicator which would have a user friendly format and which would enable us to implement a life cycle assessment. After consultation with the management of PintInox, S. p. A., we decided to use the ecological footprint. The latter is also available in the form of an easily accessible web-based tool, and an Austrian version of the ecological footprint was available through the university, which has made the tool reliable. The ecological footprint relates economic/ business activities to the ecosystem by offering the possibility to convert economic dimensions into environmental dimensions. The maximum capacity of our ecosystem is represented by the surface area of our planet Earth. The anthropogenic impact (represented by economic activities) on the environment which is measured and transferred into square meter of earth surface cannot exceed the area of planet Earth. Otherwise, the anthropogenic activities cannot be considered sustainable. Obviously, a single small- or medium-sized enterprise cannot track the ecological footprint of all companies in the world and, based on this information, derive its own allowable output in square meter. Today, 
there is no option to calculate something like that (see Equation 1).

$$
S_{1}+\sum_{2}^{n} S \leq S_{\text {planet }}
$$

where $S_{1}$ is the earth surface occupied by activities of selected SME, $\sum_{2}^{n} S$ is the surface occupied by other entities in the economy, and $S_{\text {planet }}$ is the total surface of planet Earth.

Consequently, the only strategic move a company can effectively make on its own initiative is to declare a real (measurable) commitment to the environment and society. One of the best solutions is to work out a policy or a strategy which will effectively reduce the negative environmental impact.

\section{The uniqueness of the proposed method}

The main goal of the presented initiative is to help SMEs to apply sustainability measurement metrics in a manner that will not jeopardize their ability to successfully compete in the market (it should even boost their ability to compete rather than jeopardize it). The paper presents a concept of sustainability implementation by respecting the business limitations (e.g., the economic effectiveness). Companies can accept a philosophy of sustainable development only to an extent which will not endanger their ability to compete in the marketplace. The principle is not to insist on compulsory levels of rescued square meter of earth surface but to take into account an environmental dimension in a way that managers would voluntarily lower the environmental impact in cases when it is economically feasible (i.e., the preference of a market-based approach to a command-and-control approach). In other words, this paper offers a methodology that companies can employ to boost their competitiveness by realizing sustainability-friendly decisions. There must be a number of market incentives which support the evolution of verifiable Corporate Social Responsibility as a functional concept. If we want to make our planet habitable in the future, we must find approaches to realize sustainable development. The aim is to implement new principles within the boundaries of those impacting the environment most - the SMEs (the SMEs contribute an amount of at least $70 \%$ of industry-related environmental damage due to the fact that the damage is caused by $99 \%$ of all companies in Europe [6]). However, this would not be possible without respecting their primary objective, which is in general to remain competitive. These seem to be contradictory goals - to help SMEs to implement climate-friendly processes whilst not jeopardizing their ability to remain competitive. The resolution of this situation lies in the successful implementation of sustainable development principles in the form of a welltargeted and well-performed business strategy. In other words, the implementation of an innovation lowering environmental impact will come at a cost, but if customers are willing to pay for that, then it would be a win-win situation for a company and society. The key to a successful implementation of verifiable and trustworthy sustainable measurement metrics is the consecutive successful commercialization of the results of this activity.

\section{Markets placing value on sustainable development}

One of the main characteristics of every business is the natural willingness of every company to remain competitive. Another important feature is that an innovation must be marketable, as seen from a business perspective. Otherwise, it would be easily forgotten. Taking these into consideration, this paper strongly concerns itself with the new thriving market which places value on sustainability principles - customers expect responsible behavior from companies and buyers, whereas the latter require responsible behavior from their suppliers and push in this way the responsible entities directly into the acceptance of the sustainable development philosophy. For example, a large company such as the ACCOR hotel chain could have decided to choose only the threshold suppliers. It would therefore not be possible for the company to exceed this threshold with any other products. The threshold could be measured using ecological footprints. Products exceeding the maximum footprint would not be procured by such a large company. This could be one of the ways in which barriers to entering a market principle, applying value to sustainable development for SMEs characterized by their low environmental performance, could be overcome. Other authors also mention the role of markets in the dissemination of sustainable development principles:

- Local markets for combustible waste in Europe are gradually opening up, and a liberalization of trade in products, such as paper and plastics, has created a thriving international market that valorizes secondary resources and improves the treatment efficiency [7];

- Life cycle assessment has become an important issue for products and services, since environmental concerns become increasingly decisive for the admission to markets as well as customer's decisions [5].

\section{Implementation in SMEs}

This paper was prepared in cooperation with PintInox, S. p. A., an Italian SME. Small- and medium-sized enterprises are the key element in decarbonizing the economy. Those SMEs employ $66.9 \%$ of the European labor force and form $58.4 \%$ of the total Gross Value Added produced by private businesses in the EU in 2010 [8]. The cooperation 
with small- and medium-sized enterprises from Lombardy dates back to 2011, when the initial parts of the assessments were carried out. The selected geographical field of research was Northern Italy. This paper focusses on the implementation phase of an innovative and sustainable product. Figure 1 depicts the life cycle of this product. In a time period from 2011 to 2012, we performed pioneering sustainability measurements of the internal processes in the company. We were then able to create a knowledge base used for the elaboration of a pioneering Corporate Social Responsibility concept based on the existing efforts leading towards sustainability. In our work, we discovered ecoinnovations that had already been realized and that had not yet been labeled with an ecological label, because the company management did not have the relevant metrics which provided the evidence of sustainability. By the identification of already elaborated environmental innovation, we realized that one of the traditional managerial beliefs, stating that an orientation on sustainable development is undoubtedly a money-consuming activity requiring additional investments, did not hold true. Figure 2 illustrates an example of our assessment results. The company produced their model Sirio in 1987 with successive innovations in the design realized in 1991 and 2004. Those innovations were responsible for savings in the raw material used, and therefore, calculated by using the ecological footprint, $9 \mathrm{~m}^{2}$ of earth surface was rescued per one item produced. This is a result that could be compared with the threshold set up by a large company (i.e., a potential buyer of an 'eco-innovated product'). Provided the savings in footprint were enough/ satisfactory for a buyer, then the 'sustainability market entrance barrier' could be overcome.

The aim of this paper is not only to describe the pioneering sustainability assessment processes for a selected company but also to fill the gap in sustainability assessments in terms of integrative assessment processes. An integration of technical (e.g., footprint) and economic assessments (e.g., game theory) is needed but has been sporadic until now. In other words, companies need to think holistically in realizing eco-innovation. The holistic view has to be incorporated in the assessment of the ecological and social performance of a concrete sustainable idea (to prove and to verify that it is really a sustainable solution) along with the assessment of the economic feasibility of this sustainable idea under real market conditions. Sustainability initiatives strive for commercialization; otherwise, the philosophy of 'being sustainable' and 'behaving responsibly' can hardly be widespread. This study is devoted to an analysis of the market because selling to the end customer is the most critical phase of a product's life cycle, determining its success or failure. In Figure 1, the most critical point in a life cycle (the market penetration), determining the success or failure of a concept, is presented.

\section{The aims of the study}

The broader aim of this study was to describe the steps necessary to analyze whether the sustainable idea (e.g., environmental innovation) is environmentally compatible, socially acceptable, and economically viable. In simple words, we have searched for a viable business solution reducing the negative anthropogenic impact. In our opinion, the most important steps are the specification of the sustainability measurement metrics to be used drawing attention to the fact that the implementation of these metrics cannot endanger the competitiveness of companies applying them. The specific research aims of the study were as follows:

(1) Within the life cycle of a product, the specific aim in terms of the market penetration phase is to analyze the potential success of a product at markets assigning value to principles of sustainable development (markets based on sustainability);

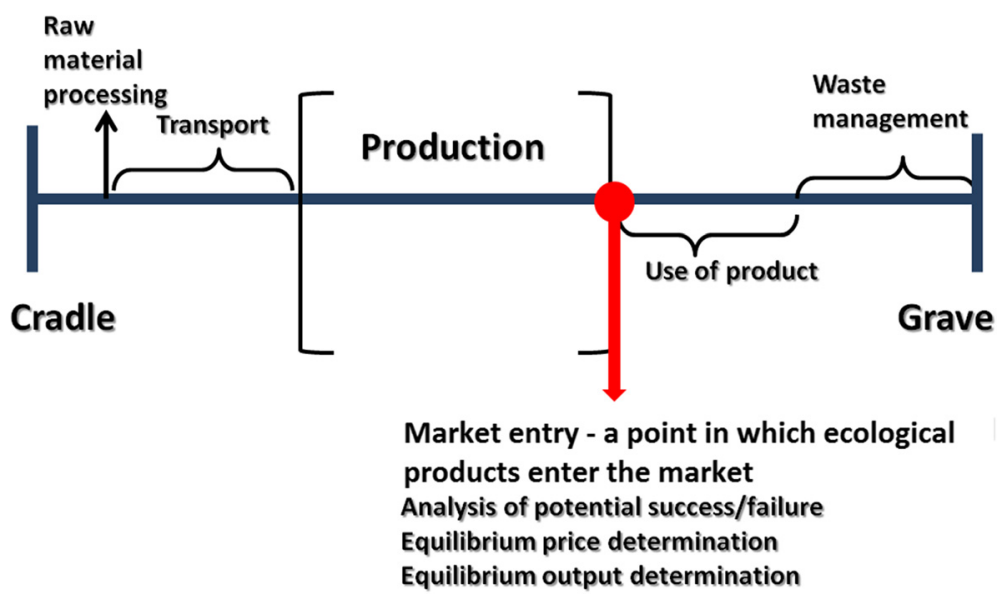

Figure 1 Critical point of life cycle - analysis of market penetration. 


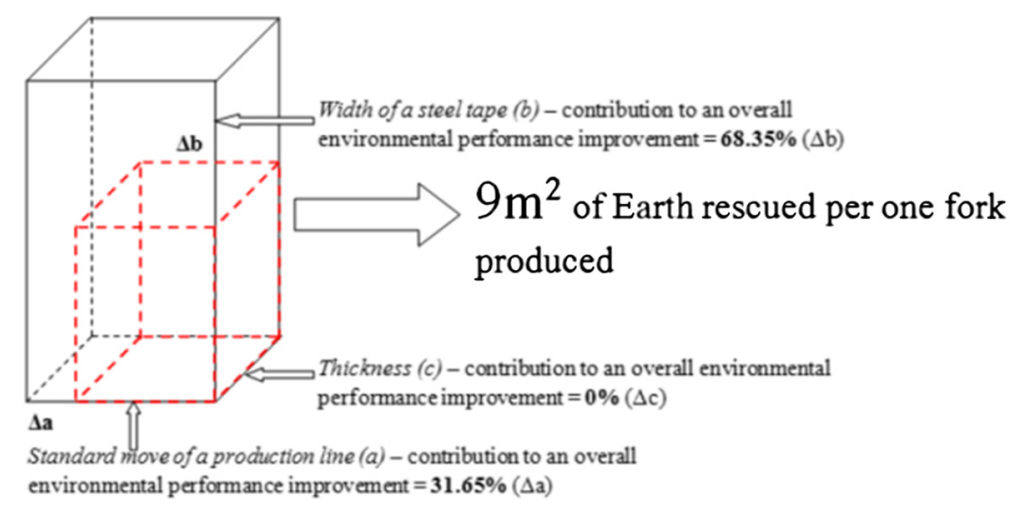

Figure 2 Environmental innovation discovered for a production plant.

(2) to provide an example to be followed, showing companies how they can commercialize their newly introduced concepts of Corporate Social

Responsibility; and

(3) to present a methodology that other companies can use in order to predict their potential success using market principles based on sustainable development.

\section{Methods}

\section{Game theory in general}

The game theory (interactive decision theory) is a key tool used in this study as a part of the implementation of sustainability measures in business. It is a rational interaction of counterparts (labeled by the game as players). In business-to-business (B2B) relations, there are numerous interactive situations that can be analyzed by the game theory. In our case, the game theory is utilizable in the identification of the behavior of smaller business entities in relation to large companies (B2B customers) that already have a significant interest in sustainability. The interest of large companies in sustainability is derived from their understanding of this concept as a marketing advantage (when applied as a differentiation strategy) or, in some cases, as an incentive to preserve material and energy resources (economy and ecology are sometimes in symbiosis - they both want to 'consume less'). Large companies, after establishing their own internal environmental certification, 'prescribe' social responsibility to their suppliers (e.g., the obligation posed to supplier SME to deliver life cycle assessment information about supplied products, the obligation to prove a functional Corporate Social Responsibility policy using verifiable metrics). It is generally agreed that the first formal theorem in the theory of games was proven by E. Zermelo in an article on chess that appeared in German in $1913^{\mathrm{a}}$. However, a game theory contains several of topics (monopolies, law of demand, competition) that existed independently of the game theory ${ }^{\mathrm{a}}$ itself. Today's Cournot game principles were brought to the forefront by Antoine
Augustin Cournot in 1838 in the book 'Recherches sur les principles mathématiques de la théorie des richesses' (who studied the mathematical principles of the theory of wealth) but have not referred to the game theory rules since that time ${ }^{\mathrm{b}}$. This means that the principles did not exist in the form that we know them today. To summarize briefly, the very first time when an interactive decision theory was professionally used and labeled as a game was in the relation to saloon games and is dated back to the year 1913. Today, the game theory is being used in economics, political science, military strategic and tactical decisions, computer science, evolutionary biology, and a more recent field of application - the sustainable development. The game theory analyzes behavior and interaction of economic agents. To date, 15 scientists have been awarded The Sveriges Riksbank Prize in Economic Sciences in Memory of Alfred Nobel for their work, which either directly or indirectly contained game theory principles (very recent laureate dealing with the game theory is Jean Tirole, for the year 2014). The 2012 laureates, Alvin E. Roth and Lloyd S. Shapley, have also studied how societies allocate resources ${ }^{\mathrm{c}}$.

\section{Game theory application}

Promising markets placing value on sustainability already exist. Such markets are not being created by governmental regulations but by large companies themselves. This situation is being partially triggered by ISO 14040 , which requires companies to proceed with life cycle assessment. Large companies are therefore requiring their suppliers to deliver information about the previous phases of the life cycle. This interaction between large companies and their suppliers is responsible for the creation of a new market applying value to sustainability. The following sections of the paper contain the interactions of competitors of these types of promising markets. The Cournot game is being used for the analysis of this interaction. The following sections also describe the entrance barriers that this new market type typically lays 
down for those not pursuing a Corporate Social Responsibility policy. The game theory in this paper analyzes the market situation being created by a supply chain successor - the Accor hotel chain (a traditional B2B customer of cutlery producers) and the competitive response of cutlery producers willing to penetrate the market created by the Accor hotel chain by meeting the sustainability criteria being set by the Accor hotel chain to be met by its suppliers. The game theory is here in a position to drive the SMEs towards sustainability.

\section{Orientation on sustainability as a source of competitive advantage}

Due to disparities between Italian labor standards and Asian labor standards, an Italian company will never be able to match Asian cost-effectiveness. In the opinion of Italian managers, the scarce concern for health and safety rules and precarious employment makes some Asian companies more cost-effective in comparison to Italian companies. Italian companies have optimized their production automation and employ the minimum workforce required. However, with other factors (e.g., material effectiveness, pace of production, highinnovation potential), the director of marketing considers their ability to realize a cost leadership strategy as very limited. After cooperation in a field of implementation of sustainable practices, he believes that a sustainable development philosophy is one of the very few possibilities to successfully remain competitive with cheaper Asian companies. The emergence of thriving markets placing value on triple bottom line principles means that there is a market space which cannot be entered by companies with low social and environmental performance. This paper introduces the Cournot game theory as a tool enabling companies to analyze their potential to succeed in these new markets. Large companies with their environmental obligations posed to their suppliers are direct creators of such markets. Those suppliers unable to meet the prescribed environmental standards are automatically deterred from this market assigning value to principles of sustainable development. In other words, environmental standards are considered as entrance barriers for competitors with low social and environmental performance. For example, a footprint threshold set up for supplier's products could be one of the measurable and clear entrance barriers.

\section{Introduction to a Cournot game}

In terms of comparability of environmental and social performance of entities (e.g., companies, municipalities, departments), standardized indicators are necessary. The negative side of standardization is the reductionism, the loss of certain dimension. In our opinion, there is a unique value mind-set behind all sustainability measurement metrics, and this mind-set is expressed in the willingness to prioritize things and to compare them. The game theory applied within the sustainable development field cannot have an ambition to measure environmental impact, but its role is to help identify the best economic decisions that will lead companies to the new type of market, giving them information about their potential success/failure in the market. Economic advice given by the game theory is as follows:

- How costly, in terms of economic effectiveness, should the pioneering sustainable steps be;

- how much should a company ideally invest into eco-innovations;

- how much the ideal technology, ensuring the presence in the new type of market, could cost; and

- what is the ideal bulk of production?

In this paper, we decided to use the game theory as one of the assessment tools that are usually categorized as sustainability measurement metrics. Using the Cournot game theory, we are capable of thinking in another dimension - the dimension of competitiveness. Using a system of equations (polynomial equations of the second degree), we can shift from the cost dimension to the competitiveness dimension. In the course of the identification of the competitiveness of a product, which went through an eco-innovation process, we firstly observe the total costs of a production (including labor costs and overheads). In general, we need to make this observation in every company which would like to enter a market value on principles of sustainable development. The other data needed represent the market space to be served. To derive a demand function, we need to know the required amount of products and prices a buyer will accept. Using linear regression splines, we derive at the cost function of every competitor willing to enter the market. Profit functions, derived from demand and cost functions, represent payoff functions. First-order conditions for the maximization of the profit of each company lead to a system of linear equations. Solving the system of equations will underscore companies with positive and negative outputs (produced amounts of eco-friendly products). An economic interpretation of a negative output is zero production - such a company will have failed to deliver its eco-products to the market. To correctly complete this mathematical analysis, additional verifications are inevitable - after a second-order condition test, we define intervals of feasible outputs because we exclude intervals of outputs for which cost functions do not have an economic interpretation.

\section{Demand function derivation}

The main purpose of the Cournot game was in our case to identify how successful a company would be under real market conditions. The market actors are as follows: 
- PintInox, S. p. A.;

- Other SME competitors of PintInox, S. p. A., with an adequately elaborated Corporate Social Responsibility (CSR) policy; and

- Large companies in the role of buyers (B2B partners, market creators) from PintInox, S. p. A., and other competing SMEs.

This new type of market is only accessible for companies with verifiable economic, social, and ecological performance and with a reliable orientation towards sustainable development. As we have already mentioned, the decision as to which competitors are admitted to the market should be made by the demand creator - the large company in this case. In the game á la Cournot, the company's strategies are quantified. The companies simultaneously choose their respective output levels $q_{i}$ from feasible sets $Q_{i}=[0, x)$ [9]. They sell their output at a market-clearing price $p(q)$, where $q=q_{1}+q_{2}+\ldots+q n$. The company's total profit is then generally expressed by an Equation 2 and Cournot reaction functions specifying each company's optimal output for each fixed output level of every opponent in the game ((3) and (4)).

$$
\begin{aligned}
& u_{i}\left(q_{1}, q_{2}\right)=q_{i} p(q)-c_{i}\left(q_{i}\right) \\
& r_{i}: Q_{-i} \rightarrow Q_{i} \\
& r_{j}: Q_{-j} \rightarrow Q_{j}
\end{aligned}
$$

where $c_{i}:[0, \infty) \rightarrow[0, \infty)$ is company $i$ 's cost function and $Q_{-i}$ is the sum of the outputs of all the members of the oligopoly except competitor $i$. PintInox, S. p. A., is in our game with its competitors from Italy. Asian low-cost competitors were not able to enter this market due to their inability to come up with a functional and verifiable Corporate Social Responsibility policy - which enables companies in Italy to create a natural oligopoly composed of Italian companies. Large companies (e.g., the ACCOR hotel chain, COOP Italia) have set environmental rules for their supplier SMEs. Such rules are in the form of an internal environmental policy and set requirements for SMEs (SMEs are considered as potential business partners):

- The ACCOR hotel chain ('Planet 21 certification') involves partners in the sustainable development strategy and integrates them into a responsibility process. Purchasing contracts have to be in compliance with 'Procurement charter 21';

- COOP Italia ('10 principles of COOP environmental policy') - requires a reduction in transportation distance, a better utilization of raw materials, and the tracking of the environmental impact of the production process happening on the suppliers' production site and involves the education of business partners.
In our investigated case, non-compliance with the sustainability requirements posed by large companies automatically repelled the SMEs (suppliers) from business deals with a large company. Decisions regarding who would be admitted and which cooperation would be terminated were based on the actual measured environmental and social performance. Based on the delivery of the required sustainability measurement metrics results, the first pre-selection of SMEs is carried out. A natural oligopoly of SMEs fulfilling the requirements in the application of sustainability measurement metrics is created during this step. Since the triple bottom line of sustainability is composed of three equal dimensions, in the second step of the market selection, the economic dimension plays its role. In this paper, the Cournot game forms the economic part of sustainability measurement metrics and can be considered as a complex economic indicator. Based on economic effectiveness, the Cournot game defines a market space every competitor in a formed natural oligopoly is able to fulfill. The Cournot game is in this paper presented as an internal part of sustainability measurement metrics. For the explanation of natural oligopoly, this paper uses a definition provided by $M$. Horniaček, as it allows companies in the industry to have different cost functions - which will likely be true for our case. The definition of a natural oligopoly in a single product industry is as follows ((5) and (6)) [10]:

Let $m$ be the number of types of products considered in the model, $f^{(k)}$ the set of companies capable of producing type $k \in\{1, \ldots, m\}$ of product, $Y_{j}=\left[0, \chi_{j}\right]$ the set of feasible output levels of the company $j \in J^{(k)}$, and $\chi_{j}$ the maximal feasible output of the company $j$; we can define a natural oligopoly as follows:

Considering $k \in\{1, \ldots, m\}$ and output $Q_{k} \in\left(0, \Sigma_{j \in J(k)} X_{j}\right]$, a set of companies $J^{(k)^{*} \subseteq} f^{(k)}$ with $\#\left(J^{(k) *}\right) \geq 2$ is a natural oligopoly in the industry producing type $k$ of a product with an output level $Q_{k}$ provided there exists an output vector $y^{(k) *} \in \prod_{j \in J}(k) * Y_{j}$ such that

$$
\sum_{j \in J}(k) * Y j^{(k) *}=Q_{k}
$$

and

$$
\begin{aligned}
& \sum_{j \in J}(k) * c_{j}\left(Y_{j}^{(k) *}\right) \leq \sum_{j \in J}(k)_{1 Y_{j}} \\
& \quad>0 C_{j}\left(Y_{j}\right), \forall y \in \prod_{j \in J}(k) Y_{j} \text { with } \sum_{j \in J}(k) Y_{j} \\
& \quad=Q_{k}
\end{aligned}
$$

The market demand is being represented by the Accor hotel chain and is geographically limited to Italy. Hotel chains are typical B2B customer of PintInox, S. p. A., and its competitors. The demand is being represented by 65 hotels residing in Italy and belonging to the Accor chain (Mercure, Sofitel, Ibis, Novotel). We assume one 
typical product of PintInox, S. p. A., and its competitors (a fork in this case) per one hotel guest. We have presumed the full utilization of the hotel capacities, i.e., the maximum allowed amount of guests in a hotel room (standard or family rooms). The total demand for Italy is then 8,766 forks. We have considered only hotels with internal certification 'Planet 21' because this form of standardization is the key element in setting up sustainability boundaries. A hotel which possesses this certification (assigned by Accor headquarters) should track the origin of raw and auxiliary materials being used during the previous phases of a life cycle of products and being purchased by the hotel management. As we have already mentioned, hotel chains are one of the traditional B2B customers of cutlery producers, and in this case, the Accor is a direct creator of a market based on sustainability principles. This market is closed for competitors with weak environmental performance, as cost-effectiveness itself does not represent a competitive advantage here. After the selection of a price from the catalogue and the discussion with the management about the potential demand referring to the modeled price, we set up an inverse demand function (8) from the demand function (7). The coefficients of the function were obtained using regression analysis.

$$
\begin{aligned}
& Q_{d}=8,787-104 P \\
& P=84.5-0.009 Q=84.5-0.009\left(q_{1}+q_{2} \ldots \quad+q_{n}\right)
\end{aligned}
$$

\section{Cost function derivation}

We started our game with 11 eco-friendly and responsible players. We identified 10 direct competitors of PintInox, S. p. A. in Italy; however, we did not go into further specifications of each of them, since we did not have direct access to their facilities. We assumed their levels of production costs as similar to those of PintInox, S. p. A. In this industry, every company has detailed knowledge about technology variations typical for cutlery production and their related costs. In the sample of 10 companies, we compare various cost levels of the production of an identical product (a model Sirio produced by PintInox, S. p. A., and related substitutes made by different companies). Small differences in the technology used were expressed by the pace of production. The higher the time donation to produce one product (a fork), the less innovative technology was used. The cost functions we derived for every company in a game are based on 30 observations occurring during 1 week. In PintInox, S. p. A., we observed a production process of a model Sirio (fork) during 1 week. We took into consideration fixed and variable costs.
- Fixed costs: Total production costs of a shearing form used in the cutting process to cut the exact shape of a fork;

- Variable costs: Salaries and wages, material costs, and other types of costs influenced by a change in the amount of production.

There are many more obligations that PintInox, S. p. A., has to fulfill on a periodic basis in comparison with the cheap Asian producers (e.g., prescribed probation period, equal opportunities, compulsory content of labor agreement, classification of work types in the metal industry and related remuneration). The variability of costs in our game was influenced by the employee operating the machine during our observation. During 1 week, four employees belonging to a different category each (based on the character of duties, difficulty, and work experience) were rotated at the observed workplace. The monthly salary levels in effect from the 1st of January 2012 are depicted in Table 1. Using linear regression splines, we derived a cost function for PintInox, S. p. A., and for the 10 Italian competitors. In the dataset, there are three samples for every competitor - total costs (TC), amounts produced $\left(q_{n}\right)$, and amounts produced squared $\left(q_{n}^{2}\right)$. The size of each sample is represented by the number of observations - 30 . We employed a technique known as 'curvilinear regression analysis'. The data was fitted to the model using polynomial regression, and a polynomial equation of the second degree was derived. In order to explain this situation, we have to delve deeper into this analysis and to firstly explain the use of degrees of freedom, as it is important for the $t$-statistic. The degrees of freedom are given by the number of observations minus the number of coefficients in the fitted regression model [11]. According to the lecture material of the University of Iowa, for a quadratic curve model, this gives n-3 since we are fitting two slopes and one intercept ${ }^{\mathrm{d}}$. Having 27 degrees of freedom, the critical value for t_.025 one-tailed and t_0.05 two-tailed is 2.052. Using the critical value approach, we computed $t=-1.495$ [(coefficient -1$) /$ standard error]. So, for a

Table 1 Prescribed minimum monthly salary levels

\begin{tabular}{ll}
\hline Category & $\begin{array}{l}\text { Monthly salary levels in effect from 1st of } \\
\text { January } 2012 \text { (EUR) }\end{array}$ \\
\hline 1st & $1,206.23$ \\
2nd & $1,327.19$ \\
3rd & $1,466.17$ \\
4th & $1,528.32$ \\
5th & $1,634.56$ \\
5th superior & $1,748.28$ \\
6th & $1,876.27$ \\
7th & $2,038.21$ \\
\hline
\end{tabular}


linear coefficient, we do not reject the null hypothesis at a level of .05 since $t=|-1.495|<2.052$. For a quadratic coefficient, we do not reject a null hypothesis at a level .05 since $t=|-0.99|<2.052$. From the statistical point of view, we are not able to confirm causality between the level of output and total costs in PintInox, S. p. A. In the case of the competitor's data, there are two competitors of 10, where we are not able to reject the $\mathrm{H}_{0}$ hypothesis. This does not mean, we have to accept $\mathrm{H}_{0}$. The data from the regression analysis are used in the Cournot game, which represents the sustainability decision support tool. The data feed will be realized by companies, and the decision will be theirs as to what kind of 'typology' of competitors they will choose; they may create various scenarios based on different cost levels of production. The data in our case are from the actual production plant and were confirmed by the management of the cooperating company. The competitor's data were also confirmed as one possible scenario. Therefore, we consider them relevant and trustworthy. The computed cost functions based on regression analysis are as follows:

$$
\begin{aligned}
& 0.0055 q_{1}^{2}-3.5306_{q 1}+5,562 \text { Pintlnox } \\
& -0.0408 q_{2}^{2}-19.78_{q 2}+4,184 \text { Competitor } \mathrm{x}_{2} \\
& 0.0007 q_{3}^{2}-1.08 q_{3}+5,573 \text { Competitor } \mathrm{x}_{3} \\
& -0.0017 q_{4}^{2}+4.02 q_{4}+5,096 \text { Competitor } \mathrm{x}_{4} \\
& -0.0130 q_{5}^{2}+7.43 q_{5}+4,567 \text { Competitor } \mathrm{x}_{5} \\
& -0.0056 q_{6}^{2}+8.42 q_{6}+4,402 \text { Competitor } \mathrm{x}_{6} \\
& -0.0075 q_{7}^{2}+10.49 q_{7}+4,540 \text { Competitor } \mathrm{x}_{7} \\
& -0.0241 q_{8}^{2}+22.7 q_{8}+3,951 \text { Competitor } \mathrm{x}_{8} \\
& -0.0031 q_{9}^{2}+6.55 q_{9}+4,818 \text { Competitor } \mathrm{x}_{9} \\
& 0.0021 q_{10}^{2}+0.61 q_{10}+5,681 \text { Competitor } \mathrm{x}_{10} \\
& 0.0088 q_{11}^{2}+0.002 q_{11}+4,930 \text { Competitor } \mathrm{x}_{11}
\end{aligned}
$$

Regression analysis based on the data from PintInox, S. p. A. is available in the Additional file 1; regression analysis based on the data from competitors is available in the Additional file 2. Initial demand function is available in the Additional file 3, and residual demand function is available in the Additional file 4. Additional file 5 contains geographical distribution of hotels in Italy that were considered for derivation of demand functions. The detailed calculation description is available in the Additional file 6.

\section{Results and discussion}

This paper has reconfirmed that for companies excluded from the Cournot game due to zero production levels or those which have not conformed to the second-order condition, it is not in their interest to reenter the Cournot game. The Cournot game's results have actually shown the optimal output for each fixed output level of every opponent in the game of companies.

In Figure 3, we can see the overall satisfaction of the market demand, represented by sold quantities of every competitor. For a better recognition, the sold quantities are available in Table 2. From 11 competitors that adhere to the principles of sustainable development, only six were able to enter the market based on the triple bottom line of sustainability. The reason for not entering was at this time the insufficient economic effectiveness (despite the fact that the environmental performance of these competitors was acceptable). The Cournot game helps companies to obtain a picture of their competitiveness and abilities to place a certain amount of environmentally friendly production within the market. The game should be in a reality based on the collections of data (production costs) mutually exchanged by economic departments of competing companies. The English word 'competition' is 'competere' in Latin and does not mean to act against one another but means to search for something together. Having competitors exchanging information about their production costs is surely a thought-provoking piece of information worth thinking about. The Cournot game is a tool with an ability to draft the potential situation of the market that is typically evaluated using the triple bottom approach - especially in that case where the sustainable development philosophy is one of the very few possibilities of how to contend with low-cost competitors. This paper offers clear guidance on the determination of

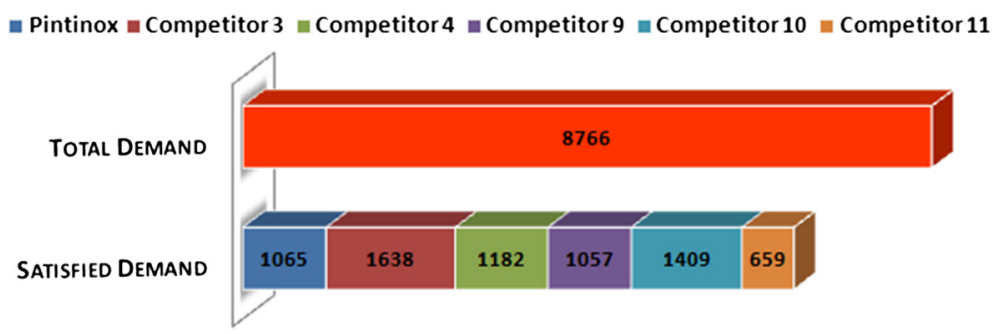

Figure 3 Total initial demand versus real satisfied demand. 
Table 2 Final subgame perfect equilibrium

\begin{tabular}{lll}
\hline$q_{1}=1,065$ & $q_{3}=1,638$ & $q_{4}=1,182$ \\
$q_{9}=1,057$ & $q_{10}=1,409$ & $q_{11}=659$ \\
\hline
\end{tabular}

Italics refers to PintInox, S. p. A. data.

the potential success or failure of Corporate Social Responsibility policy concepts. The guidance given assists company managements in the determination of the salable quantities of their production. In other words, the Cournot game represents a method to preserve the natural resources (amounts that are not needed would not be produced). In Figure 4, the sold quantity is compared to a weekly production program. From this figure, it can be concluded that a company's management could reconsider their production program. During a 1-week observation of a production line, the company manufactured 11,840 pieces (forks) whilst the sold amount, according to the Cournot game results, totalled 1,638 pieces. Which means that 10,202 pieces would not be sold, i.e., considered for the market. Stainless steel used to produce this unsold quantity caused an environmental impact of 4,682,718 $\mathrm{m}^{2}$ of consumed earth surface. If there are no additional markets where the excess amounts could be sold or if there is no potential to discover new markets for this surplus production, then (based on the Cournot game information about saleable quantities) management should reassess the volumes produced daily. Management should assume a smaller number of daily production quantities and to 'play' the Cournot game once again with lowered amounts of production. Using various scenarios, management would be able to prepare more alternatives (each with different input data) in order to determine a more sustainable production program. A simulation of the market situation by 'playing' the Cournot game would assist management in preparing a more sustainable production program. This means that a decrease of unsold quantities would be accompanied by a lower footprint. Excessive amounts of production are common phenomena, as witnessed during the post-Christmas period ('Day-After-Christmas-Sales') when huge amounts of unsold products are sold undervalue. The Cournot game represents the economic side of the triple bottom line (TBL) reporting. The Cournot game is therefore an integral part of sustainability measurement metrics.

Some large companies have already discovered situations in which economy and ecology strive to reach the same goal - to consume fewer resources. It is cheaper if it preserves natural resources (e.g., the hotels encourage customers to reuse their towels). There are more basic incentives that drive companies towards the application of sustainability measurement metrics as the main component of their marketing strategy:

- Differentiation strategy - a need to compete against low-cost competitors;

- The image - creating an image of a responsible company, especially when serving the high-end customer segment;

- A need to fulfill requirements valid at new emerging markets placing value on sustainability; and

- Cases when the economy and ecology have the same goal.

In summary, the bonus for companies that offer eco-innovations is a gained ability to utilize an opportunity to enter new prospective markets based on principles of sustainable development. This paper did not have an ambition to present a detailed way of identifying ecoinnovations by using sustainability measurement metrics. We had concentrated on the consecutive steps in the life cycle assessment - the identification of success/failure of an eco-innovation by using the Cournot game. The Cournot

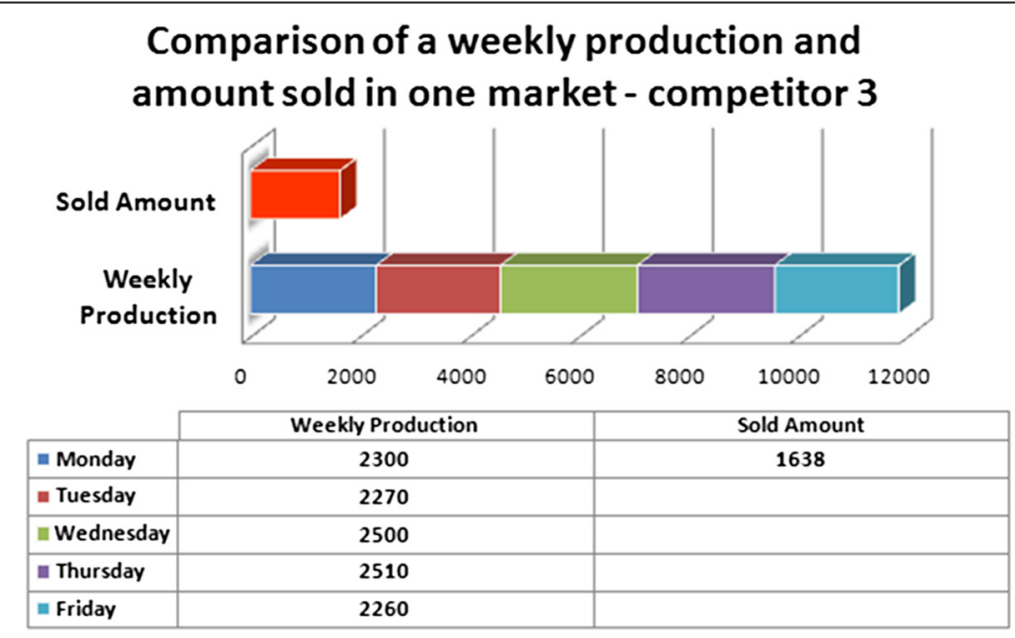

Figure 4 Production versus ability to sell the production. 
game represents the economic part of the TBL reporting. The Cournot game measures the competitiveness of companies using their CSR policy concepts and the salable quantities of their eco-innovated products.

\section{Conclusions}

In this study, the application of the game theory is a reaction to the current needs of companies, which have already applied sustainability measurement metrics. The Cournot game has a strong economic dimension, as this type of economic analysis not only derives the quadratic cost functions of competitors (using regression analysis) but also calculates the market demand and the residual market demand. In addition, it mathematically verifies the allowable production outputs and tests to find out which of the competitors cannot enter or reenter the market. The study expects the existence of market principles applying value to sustainable development. In the presented example, the SMEs had to present their commitment to society and the environment in order to access the market created by the Accor hotel chain. After admission to this market (based upon the presentation of a verifiable sustainability measurement metrics using life cycle assessment), the admitted companies form a natural oligopoly with entrance barriers for low-cost competitors and in this case become competitive with one another. In this oligopoly, economic feasibility plays a decisive role as has been evidenced by the Cournot game example. This fact reconfirms the correctness of the triple bottom line concept - environmental safety, social responsibility, and economic effectiveness play equally important roles. We do not only draw the attention of managers to the fact that Corporate Social Responsibility does have a business potential but also introduce the very complex economic part of TBL (enabling companies to fully embrace the opportunities being offered by sustainable development).

The Cournot game enables the company to think in competitiveness dimensions instead of in simple cost dimensions and delivers results utilizable in, for example, break-even point analysis. The final outcome from using the Cournot game is the ability to identify a sustainable system - which is in this case an amount of production fitted to the market needs (i.e., the salable quantities). Company managements receive a tool which protects them from overproduction. The Cournot game helps to diminish the difference between both the produced/overproduced and sold amounts. Hence, this would be the best application of the Cournot game in order to protect natural resources. From an ecological point of view, the preservation of resources means less deviation from natural cycles and from an economic point of view; it means less variable costs, less storage costs and in some cases less transportation costs. As ecological economics is a cross-discipline, we have combined the economic tool (game theory) for the evaluation of economic issues with the ecological footprint used for the evaluation of environmental dimensions in this paper. This study was prepared as a reaction to a wide gap perceived in sustainable development research in a phase of commercialization. An integration of technical and economical assessment is needed but rare. From those few studies containing an integrative assessment, the economic dimension of integrative studies is generally aimed at feasibility studies, analysis of world prices, cost benefit analysis (CBA), payback period, capital and operating cost analysis, or capital expenditures (CAPEX) analysis. However, rigorous studies of the implementation phase accompanied by market situation analyses are critically missing. The implementation and commercialization is in fact a decisive step in the life cycle of a product. The sustainable development initiatives strive for commercialization; otherwise, the philosophy of 'being sustainable' and 'behaving responsibly' can hardly be widespread. The presented paper is devoted to an analysis of the market, as selling to the end customer is in our opinion the most critical phase of the life cycle of a product which determines its success or failure. The use of a game theory is greatly underestimated by the current sustainability science. In this study, the Cournot game has a role to preserve material and energy resources. Companies limiting overproduction will directly contribute to a better future for generations to come. In this paper, it has been stated that companies cooperate within a competitive oligopoly. As mentioned, to compete ('competere') in Latin means to work on something together. A real market interaction within an oligopoly is based on economic effectiveness which is represented by the production costs. More accurate information about shared costs can be more precisely predicted by regarding the reality (the market space acquired by every competitor) in their practice. In other words, cooperation may assist them to better predict the real market situation and to prepare themselves for this goal.

\section{Endnotes}

a www.math.harvard.edu/ elkies/FS23j.03/zermelo.pdf, accessed 12. Feb. 2015.

bhttp://cruel.org/econthought/profiles/cournot.html, accessed 12. Feb. 2015.

cwww.nobelprize.org/nobel_prizes/economic-sciences/ laureates/2012/popular-economicsciences2012.pdf, accessed 12. Feb. 2015.

${ }^{\mathrm{d}}$ http://homepage.stat.uiowa.edu/ jcryer/22s008/Lecture \%20Notes/chap8.PDF, accessed 12. Feb. 2015.

\section{Additional files}

Additional file 1: Regression analysis - Pintlnox, S. p. A. Results of regression analysis based on the data from the Pintlnox, S. p. A., production plant. 
Additional file 2: Regression analysis - other competitors. The results of the regression analysis based on the developed scenarios.

Additional file 3: Initial demand function. The demand derived from the total capacity of the considered hotels in Italy - the Accor hotel chain.

Additional file 4: Residual demand function. The residual demand is calculated without the upper bounds of two competitors.

Additional file 5: Hotels - geography. Summary of all considered hotels in Italy forming a demand in our game.

Additional file 6: Calculation part of the Cournot game. Additional proofs required from the formal mathematical point of view.

\section{Abbreviations}

S. p. A.: La societá per azioni - joint stock company; B2B: Business to business; SMEs: Small- and medium-sized enterprises; CSR: Corporate Social Responsibility; TBL: Triple bottom line; CBA: Cost benefit analysis; CAPEX: Capital expenditures.

\section{Competing interests}

The author declares that he has no competing interests.

\section{Authors' information}

MD is currently employed as a research assistant at the Faculty of Economics and Business of the Pan-European University. Here, he also defended his PhD thesis in November 2013. The PhD research was being supervised by Assoc. Prof. Pavol Molnár from the Pan-European University (the first half of the $\mathrm{PhD}$ study was devoted to environmental innovations) and then supervised by Assoc. Prof Milan Horniaček from the Comenius University in Bratislava (the second half of the PhD study was devoted to the game theory). MD is a graduate of the University of Economics.

\section{Acknowledgements}

The author of the article, MD, started work in Pintlnox, S. p. A., as a master's student in 2009 doing his research fellowship funded by the Erasmus work placement program. MD has renewed his relationship with the management of PintInox, S. p. A., in June 2011 with the proposal to apply the research outcomes of this company. The approval was granted by the co-owner, Dr. Silvia Pinti. The data sources were provided by the director of the technical office, Ing. Roberto Pinti; the director of the financial office, Ing. Pinardi; and the director of the marketing department, Dr. Mauro Romani. These persons were also involved in discussions and a continued information exchange with MD.

Received: 2 December 2014 Accepted: 10 December 2014 Published online: 12 February 2015

\section{References}

1. 4th International Symposium on Energy from Biomass and Waste (2012) International Waste Working Group. Venice

2. Sanin ME, Zanaj S (2007) Environmental innovation under Cournot competition. CORE 2007/50 33:1-3

3. Montero JP (2002) Permits, standards, and technology innovation. J Environ Econom Manage 44:23-44

4. Daly H, Farly J (2004) Ecological economics: principles and applications. Island Press 449:33-75

5. Sandholzer D, Narodoslawsky M (2007) Sustainable? Processes from renewable resources, vol 15. Graz University of Technology, Institute for Resource Efficient and Sustainable Systems, Graz, Austria, pp 1-15

6. Constantinos C, Sørensen SY, Larsen BP, Alexopoulou S (2010) SMEs and the environment in the European Union. PLANET SA and Danish. European Commission, vol 238. DG Enterprise and Industry, p ii

7. Dubois M (2012) Towards a coherent European strategy for taxation of combustible waste. In: International Symposium on Energy from Biomass and Waste, vol 8. International Waste Working Group, Venice, pp 1-8

8. Wymenga P, Derbyshire J (2011) Are EU SMEs recovering? Annual Report on EU SMEs for European Commission, vol 58. ECORYS Nederland BV, Rotterdam, Cambridge, p 8
9. Fudenberg D, Tirole J (1991) Game theory, vol 579. The MIT Press, Boston, pp 80-100

10. Horniaček M (2011) Cooperation and efficiency in markets. Lecture notes in economics and mathematical systems, vol 649th. Springer, Heidelberg, doi:10.1007/978-3-642-19763-5

11. Schlotzhauer SD (2009) Elementary statistics using SAS. SaS Institute Inc, New York

\section{Submit your manuscript to a SpringerOpen ${ }^{\odot}$ journal and benefit from:}

- Convenient online submission

- Rigorous peer review

- Immediate publication on acceptance

- Open access: articles freely available online

- High visibility within the field

- Retaining the copyright to your article

Submit your next manuscript at $\boldsymbol{\triangleright}$ springeropen.com 